\title{
Factors associated with timely initiation and exclusive breast feeding among mothers of Axum town, Northern Ethiopia
}

\author{
Mussie Alemayehu ${ }^{1,}$,,$K_{i d a n}$ Abreha $^{1}$, Henock Yebyo ${ }^{1}$, Kahssay Zemichael ${ }^{2}$ \\ Hailay Gebremichael $^{3}$ \\ ${ }^{1}$ Department of Public Health, Mekelle University College of Health Sciences, Mekelle, Ethiopia \\ ${ }^{2}$ Axum District health office, Axum, Ethiopia \\ ${ }^{3}$ School of Medicine, College of Health Sciences, Mekelle University, Mekelle, Ethiopia
}

\section{Email address:}

mossalex75@gmail.com (M. Alemayehu),KahssayZemichael@gmail.com (K. Zemichael), kidanabrha@gmail.com (K. Abreha), henokyebyo@yahoo.com (H. Yebyo), hagept@yahoo.com (H. Gebremichael)

\section{To cite this article:}

Mussie Alemayehu, Kidan Abreha, Henock Yebyo, Kahssay Zemichael, Hailay Gebremichael. Factors Associated with Timely Initiation and Exclusive Breast Feeding among Mothers of Axum Town, Northern Ethiopia. Science Journal of Public Health.

Vol. 2, No. 5, 2014, pp. 394-401. doi: 10.11648/j.sjph.20140205.14

\begin{abstract}
Background: Globally, there is a declining in the trend of breast feeding. Moreover, inappropriate practice of timely initiation and exclusive breastfeeding affects negatively on child survival, growth and development. One in every 11 and 17 Ethiopian children dies before the first birthday and the fifth birthday, respectively. However, one of the priorities, in the Health Sector Development Plan (HSDP) IV is improving child health, with a goal to reduce the under-five mortality rate. This study aimed at assessing the proportion and factors associated with timely initiation and exclusive breastfeeding among mothers in Axum town. Methods: A cross sectional study was conducted in Axum Town from May 10-26, 2013 to collect data from 418 mothers having children less than one year old using a systematic random sampling. Descriptive and multiple logistic regression analyses were performed using SPSS 20 for windows to estimate indicators and effect sizes of the predictors on timely initiation and exclusive breastfeeding. Results: The overall proportion of timely initiation and exclusive breastfeeding was, 41.6 and $40.9 \%$, respectively. Mothers with female child and those who didn't give colostrums to their newborn within an hour after birth had a positive association with timely initiation of breastfeeding with AOR of 2.09 (95\% CI: $1.37,3.17)$ and AOR of $0.31(95 \%$ CI: $0.20,0.48)$. Moreover, mothers who didn't give the colostrum to their newborn within an hour after birth were less likely to practice exclusive breastfeeding than their counterparts AOR of 0.13 (95\% CI: $0.08,0.21)$. Conclusion: The proportion of timely initiation and exclusive breastfeeding was low. Giving colostrums could have an influence on timely initiation and exclusive breastfeeding. Besides, child sex could have an influence on timely initiation of breastfeeding.
\end{abstract}

Keywords: Timely Initiation, Exclusive Breastfeeding, Axum, Tigray, Ethiopia

\section{Introduction}

Breastfeeding is the process of feeding the infant with mother's milk [1]. World Health Organization [WHO] recommended that, breastfeeding should start immediately within one hour following of delivery for the baby to get colostrums. The infant should thereafter be exclusively breastfed for up to six months of life, day and night on child's demand [2]. Breastfeeding should still continue until the child is two years of age [3]. Exclusive breastfeeding is recommended because breast milk is uncontaminated and contains all the nutrients necessary in the first few months of life [4].

However, globally, there is a declining in the trend of breast feeding. The trend in declining of exclusive breastfeeding is greatly influenced by factors such as low educational level, socio- economic status, religion, marital status and occupation of mothers, lack of confidence that the mothers perceive the child is not getting milk enough, decline in social support, a feeling of discomfort on breastfeeding in public area, intense promotion of commercial milk form and lack of adequate 
information $[5,6]$.

Furthermore, inappropriate practice of timely initiation breastfeeding [TIBF] and exclusive breastfeeding [EBF] affects negatively on child survival, growth and development [1, 7]. Infants less than two months old who are not breastfed are six times more likely to die from diarrhea and acute respiratory infections than their counterparts. This is because of inadequate timely initiation and exclusively breast feeding [8]. Moreover, a good attention and efforts has not been paid by healthcare practitioners and policy makers [9].

Different studies conducted on the topic of timely initiation and exclusive breastfeeding in many parts of the world, including Ethiopia have been shown that the rates are lower than the international recommendation for the first six months of life [10]. A study conducted in Uganda has been shown that over one million newborn infants could be dying each year from lack of initiating breastfeeding within the first hour of life globally [11]. In Ethiopia, based on the report of EDHS, 2011 only 52\% started breastfeeding within one hour of birth and the prevalence of exclusively breastfed is $52 \%$. In Tigray region, only $44.7 \%$ of infants only started breastfeeding within one hour of birth, which was less than the national prevalence [4]. Besides, one in every 17 Ethiopian children dies before the first birthday, and one in every 11 children dies before the fifth birthday. However, one of the priorities, in the Health Sector Development Plan (HSDP) IV is improving child health, with a goal to reduce the under-five mortality rate to 68 per 1,000 live births and the infant mortality rate to 31 per 1,000 live births by 2015 [12]. However, this might be difficult to achieve if more effort and due attention is not given to enhancing both timely initiation of breastfeeding and exclusive breastfeeding.

The national study indicated that the existence of the problems of inappropriate practice of exclusive breastfeeding (EBF) and timely initiation of breastfeeding (TIBF) [4]. It has also a negative role in achieving MDG goals and inappropriate practice of timely initiation of breastfeeding only causes neonatal mortality of $22 \%$ [13]. So, conducting this study is very important as it enables to determine the magnitude and factors associated with timely initiation and exclusive breast feeding, because the factors may be different from place to place and culture. Moreover, the finding of this study will also help as a baseline data for those who are interested in carrying out further research in this regard.

\section{Methods}

A community based cross-sectional study was conducted in Axum Town from May 10-26, 2013. The total population of the area is 54,494 with 27,792 females. Regarding information about health service there are 2 governmental health centers, 1 referral hospital, 3 private clinics. Tigraway is the dominant ethnic group in Axum [14]. All mothers who have infant from six months to one year old were considered as source population. Mothers who were critically ill during the data collection period were excluded from the study.

To determine the sample size, a single population proportion formula with a proportion of mothers who started breastfeeding within one hour of birth in Tigray region was $44.7 \%$ [4], a confidence level of $95 \%$, and a $5 \%$ degree of precision, were used. A non-response rate of $10 \%$ was also used. The final sample size calculated was 418 mothers who have infant from six months to one year old.

Systematic sampling technique was used to select and approach the study subjects. There are four kebeles (Kindeya, Hawelti, Hayelom and Maebel) in Axum town. A total of 11,123 reproductive age mothers, 2,078 mothers with six months to one year old and 11,426 households. The total sample were shared for each Kebele based on available number of household of women with six months to one year old infants by applying proportion to size allocation. The sampling fraction $\left(\mathrm{K}^{\mathrm{th}}\right)$ was determined for the kebeles. Based on the sampling fraction, a starting woman was determined by using simple random sampling. If an individual doesn't satisfy the inclusion criteria, then the next participant would be included in the study. Structured and pre-tested questionnaire, guided by the interviewer, was used to collect the information. It was first prepared in English and then translated to Tigrigna and then translated back to English for consistency. Information collected included socio demographic and economic conditions, obstetric history, knowledge, attitude and practice of breastfeeding questions. The questionnaires were adapted by reviewing different literatures and considering the local situation of the study subjects [6, 16,17]. Twelve clinical nurses who speak local languages were employed in the data collection process. Four BSc nurses were selected as a supervisor. Training was given to the data collectors and supervisor for two consecutive days on the objectives of the study, the contents of the questionnaire, particularly on issues related to the confidentiality of the responses and the rights of respondents. One week prior to the data collection, a pretest was conducted at Adwa Town in 21(5\%) of the sample size.

The data collected was cleaned, edited, coded and entered into a computer, checked for missing values and outliers and analyzed using SPSS of windows version 20.0 (SPSS Inc. Version 20., Chicago, Illinois). Simple descriptive frequency tables and bivariate analyses were carried out. To identify the predictors of timely initiation of and exclusive breast feeding, a multivariable logistic regression model with timely initiation of breastfeeding and exclusive breastfeeding as a dependent variable were constructed. Variables that showed significant association with timely initiation and exclusive breast feeding on the bivariate analyses were entered into the adjusted logistic model. Interaction between variables was checked at the level of significance for the interaction term of $\mathrm{P}<0.2$. Multicolinarity test was also done to assess the interaction 
among the independent variables. The following operational definitions were used; Positive attitude: Mothers who scores above the mean score of to the 8 attitude related questions of TIBF and EBF. Negative attitude: Mothers who score mean and below the mean score of the 8 attitude related questions of TIBF and EBF.

The study was approved by the ethical committee of Mekelle University College of health science (MUCHS) research and community service committee. Formal letter of permission was obtained from Mekelle University and Tigray Regional Health Bureau. The official letter of cooperation from the above organization was given to the Axum Woreda health bureau. Verbal consent was obtained from the study respondents. The right of the respondent to withdraw from the interview or not to participate at all was respected.

\section{Result}

\subsection{Socio-Demographic Characteristics}

Table 1. Socio-demographic characteristics of mothers, in Axum town, Northern Ethiopia, 2013

\begin{tabular}{|c|c|c|}
\hline Variables $(n=418)$ & Frequency & Percent \\
\hline \multicolumn{3}{|l|}{ Mothers age } \\
\hline $15-19$ & 17 & 4.1 \\
\hline $20-24$ & 107 & 25.6 \\
\hline $25-29$ & 169 & 40.4 \\
\hline $30-34$ & 81 & 19.4 \\
\hline $35-49$ & 44 & 10.5 \\
\hline \multicolumn{3}{|l|}{ Marital status } \\
\hline Married & 399 & 95.5 \\
\hline Never married & 19 & 4.5 \\
\hline \multicolumn{3}{|l|}{ Ethnicity } \\
\hline Tigraway & 417 & 99.8 \\
\hline Amhara & 1 & 0.2 \\
\hline \multicolumn{3}{|l|}{ Educational status of mothers } \\
\hline Unable to read and write & 146 & 34.9 \\
\hline $1-8$ grade & 215 & 51.4 \\
\hline Secondary school and above & 57 & 13.6 \\
\hline \multicolumn{3}{|l|}{ Occupational status } \\
\hline Employed & 54 & 12.9 \\
\hline House wives & 364 & 87.1 \\
\hline \multicolumn{3}{|l|}{ Religion } \\
\hline Orthodox & 372 & 89 \\
\hline Muslim & 46 & 11 \\
\hline \multicolumn{3}{|l|}{ Monthly income } \\
\hline$<26 \$$ & 172 & 41.1 \\
\hline $26-52.6 \$$ & 192 & 45.9 \\
\hline$>52.6 \$$ & 54 & 13 \\
\hline \multicolumn{3}{|l|}{ Infants age } \\
\hline $6-8$ months & 278 & 64.5 \\
\hline $9-12$ months & 140 & 33.5 \\
\hline \multicolumn{3}{|l|}{ Sex of the infant } \\
\hline Male & 216 & 51.7 \\
\hline Female & 202 & 48.3 \\
\hline \multicolumn{3}{|l|}{ Radio } \\
\hline Yes & 258 & 62 \\
\hline No & 159 & 38 \\
\hline \multicolumn{3}{|l|}{ Television } \\
\hline Yes & 249 & 59.8 \\
\hline No & 168 & 40.2 \\
\hline
\end{tabular}

$1 \$=19.5 \mathrm{ETB}$
A total of 418 mothers who had children aged 6-12 months were interviewed making the response rate of $100 \%$. The majority of the mothers, $169(40.4 \%)$ were in the age group of 25-29 years with a mean of $26.9(\mathrm{SD}+5.01)$. The majority of the participants were orthodox in religion 372 (89\%), Tigraway in ethnicity $417(99.8 \%)$, married 399 $(95.5 \%)$ and house wives in $364(87.1 \%)$. Concerning to the educational status of the mothers, two hundred seventy two $(65 \%)$ had attended formal school, out of which $57(13.6 \%)$ had accomplished a secondary school and above. Out of the total, nearly half $192(45.9 \%)$ of mothers earn an average monthly income of 26-52.6 \$ with a median of $31 \$$. Majority of the mothers had a radio (62\%) and Television $(59.8 \%)$. Pertaining to the infant characteristics, majorities, $278(64.5 \%)$ were aged between $6-8$ months and male in sex $216(51.7 \%)$ [Table1].

\subsection{Health Service and Obstetrics Related History}

Table 2. Distribution of obstetrics and health service related variables of mothers in Axum town, Northern Ethiopia, 2013

\begin{tabular}{|c|c|c|}
\hline Variables & Frequency & Percent \\
\hline \multicolumn{3}{|l|}{ Gravida } \\
\hline One & 137 & 32.8 \\
\hline Two & 129 & 30.9 \\
\hline Three and above & 152 & 36.4 \\
\hline \multicolumn{3}{|l|}{ Number of children } \\
\hline One & 142 & 34 \\
\hline Two and above & 276 & 66 \\
\hline \multicolumn{3}{|l|}{ ANC visit history( follow up) } \\
\hline Yes & 405 & 96.9 \\
\hline No & 13 & 3.1 \\
\hline \multicolumn{3}{|l|}{ Number of ANC visits } \\
\hline One & 25 & 3.0 \\
\hline $2-3$ & 137 & 32.8 \\
\hline 4 and above & 256 & 63.2 \\
\hline \multicolumn{3}{|l|}{ Place of delivery } \\
\hline Home & 50 & 12.0 \\
\hline Health institution & 368 & 88.0 \\
\hline \multicolumn{3}{|l|}{ Modes of delivery } \\
\hline Spontaneous vaginal delivery & 403 & 96.4 \\
\hline Cesarean section & 15 & 3.6 \\
\hline \multicolumn{3}{|l|}{$\begin{array}{l}\text { History of mothers hospital } \\
\text { admission }\end{array}$} \\
\hline Yes & 27 & 6.5 \\
\hline No & 391 & 93.5 \\
\hline \multicolumn{3}{|c|}{ History of infant hospital admission } \\
\hline Yes & 12 & 3 \\
\hline No & 406 & 97 \\
\hline \multicolumn{3}{|l|}{ Breast problem $(n=55)$} \\
\hline Mastitis & 19 & 34.5 \\
\hline Breast engorgement & 27 & 49 \\
\hline Cracked nipples & 9 & 16.5 \\
\hline \multicolumn{3}{|l|}{ Birth interval } \\
\hline Three and above years & 276 & 66 \\
\hline Less than three years & 142 & 34 \\
\hline \multicolumn{3}{|l|}{ PNC visit history( follow up) } \\
\hline Yes & 234 & 56 \\
\hline No & 184 & 44 \\
\hline
\end{tabular}

A majority, $152(36.4 \%)$ of the mothers were having pregnancy three and above and two third (66\%) had two and above children. Almost all, 405(96.9\%) of the mothers had follow up of the ANC, out of this; nearly two thirds had 
attended four and above ANC visits. Midwives were the attendance of ANC service as well as for the provision of counseling on timely initiation and exclusive breastfeeding for all mothers who attended the ANC. Eighty eight percent of the mothers were giving birth to their previous baby at the health institution. Almost all, 403(96\%) of the mother had faced spontaneous vaginal delivery during their previous birth. Information regarding hospital admission $27(6.5 \%)$ mothers and $12(3 \%)$ of their infant were admitted. Only 55(13\%) mothers face, breast problem, out of which $27(49 \%)$ had breast engorgement. Above half, 234(56\%) of the mothers had attended postnatal care service for their child and $276(66 \%)$ had a birth interval of three years and above. The awareness about the purpose of TIBF and EBF was universal. Moreover, 206(48.6\%), 133(33\%) and $76(18.2 \%)$ of the mothers mentioned that health workers, media and friend were the source of information. Mothers who received information about breastfeeding during ANC visit was 279(68.9\%), while the remaining were $139(31.1 \%$ ) did not [Table 2].

\subsection{Attitude of Mothers towards TIBF and EBF}

Breast milk is free from contamination, contains all the nutrient necessary for the infant and it provides the infant with the immunity to prevent disease was agreed by $330(77.8 \%), 399(95.5 \%)$ and $330(79 \%)$ of the mothers, respectively. Moreover, the majority, 253(60.5\%) of the mothers were agreed that timely initiation of breast milk makes the infant to get liquid only, breastfeeding is enough for the baby up to 6 months $400(95.7 \%)$ and the duration of breastfeeding should be at least for 2 years $405(95.5 \%)$. However, a significant number, 248(59.3\%) and 253(60.5\%) of the mothers were disagree for dealing with breastfeeding is time consuming and breast feeding affect the posture or health of the mother, respectively [Table 3].The composite measure of attitude indicates that $363(87 \%)$ mothers had a positive attitude towards timely initiation as well as exclusive breast feeding, where as the remaining 55(13\%) had a negative attitude.

Table 3. Attitude of respondent mothers about EBF and TIBF, Axum town, Northern Ethiopia, 2013

\begin{tabular}{|c|c|c|c|c|c|c|}
\hline \multirow{2}{*}{ Attitude statement } & \multicolumn{2}{|c|}{ Disagree } & \multicolumn{2}{|l|}{ Agree } & \multicolumn{2}{|c|}{ Not sure } \\
\hline & No & $\%$ & No & $\%$ & No & $\%$ \\
\hline Breast milk is free from any contamination? & 6 & 1.4 & 330 & 77.8 & 82 & 19.2 \\
\hline Only breastfeeding is enough for the baby up to 6 months? & 2 & 5 & 400 & 95.7 & 16 & 3.8 \\
\hline Breast milk contains all the nutrient necessary for the infant & 1 & 2 & 399 & 95.5 & 18 & 4.3 \\
\hline Breast milk provide the infant with the immunity to disease & 6 & 1.4 & 330 & 79 & 82 & 19.6 \\
\hline $\begin{array}{l}\text { Timely initiation of breast milk makes the infant to get liquid } \\
\text { only }\end{array}$ & 48 & 14.5 & 253 & 60.5 & 117 & 28 \\
\hline Dealing with breastfeeding is always time consuming. & 248 & 59.3 & 160 & 38.3 & 10 & 2.4 \\
\hline Breast feed affect the posture or health of the mother & 253 & 60.5 & 140 & 33.3 & 25 & 6 \\
\hline Duration of breast of breastfeeding should be at least for 2 years. & 9 & 2.1 & 405 & 95.5 & 4 & 8.7 \\
\hline
\end{tabular}

\subsection{Practice of Timely Initiation and Exclusive Breast Feeding}

Table 4. Practice of timely initiation and exclusive breast feeding in Axum town, Northern Ethiopia, 2013

\begin{tabular}{lll}
\hline Variables (n= 418) & Frequency & Percent \\
\hline Timely initiation of breast feeding & & \\
Yes & 174 & 41.6 \\
No & 244 & 58.4 \\
Exclusive breast feeding & & \\
Yes & 171 & 40.9 \\
No & 247 & 59.1 \\
Squeeze out and throw away colostrums & & \\
Yes & 188 & 45 \\
No & 230 & 55 \\
Give the child other than Breast milk in the & & \\
first 3 days after delivery & & \\
Yes & 72 & 17.2 \\
No & 346 & 82.8 \\
What was your child given & & \\
Milk other than breast milk & 24 & 33.3 \\
Plain water & 20 & 27.7 \\
Sugar or glucose water & 12 & 16.6 \\
Fruit juice & 6 & 8.4 \\
Others* & 10 & 14 \\
When do you usually breast feed your child & & \\
On demand & 166 & 39.7 \\
\hline
\end{tabular}

\begin{tabular}{lll}
\hline Variables $(\mathbf{n}=\mathbf{4 1 8})$ & Frequency & Percent \\
\hline When the child cries & 190 & 45.5 \\
On schedule & 32 & 7.7 \\
Others** & 30 & 7.1 \\
Are you still breast feed the child & & \\
Yes & 341 & 81.6 \\
No & 77 & 18.4 \\
Start complementary feeding & & \\
Less than 6 months & 245 & 58.6 \\
At 6 months & 88 & 21.1 \\
Greater than 6 months & 85 & 20.3 \\
Who Support you during breast feeding & & \\
Husband & 142 & 34 \\
Other family members & 53 & 12.7 \\
No one & 223 & 53.3 \\
\hline
\end{tabular}

* Infant formula, tea, fresh butter and sugar salt water solution,

** On convenience and breast engorged

The prevalence of timely initiation and exclusive breastfeeding was $174(41.6 \%)$ and $171(40.9 \%)$, respectively. One hundred eighty eight (45\%), mothers squeezed out and throw away the colostrums. And only, 72 $(17.2 \%)$ of the mothers were giving the child other than breast milk in the first three days after delivery, out of this $24(33.3 \%)$ mothers gave cow milk. Surprisingly, 190 (45.7\%) mothers breastfed their child when the child cries and $341(81.6 \%)$ mothers still breast feed their child. A 
majority, 247(59.1\%) mothers were stating that they start complementary feeding before six months. Only 142 (34\%) mothers got support from their husband while they breastfeed their child [Table 4].

\subsection{Factors Associated with Timely Initiation of Breastfeeding}

In the bivariate logistic regression model, child sex, maternal age, educational status, place of delivery, employment status, mode of delivery and ANC visit were entered into the model. However, only sex of a child and providing colostrums within an hour after delivery had shown a statistically significant association with timely initiation of breastfeeding.

Mothers with female child had a positive association with timely initiation of breastfeeding with AOR of 2.09 (95\% CI: 1.37, 3.17). Mothers who didn't give colostrums to their newborn within an hour after birth had a positive association with timely initiation of breastfeeding with AOR of 0.31 (95\% CI: 0.20, 0.48) [Table 5].

Table 5. Factors associated with timely initiation of breast feeding among mothers attending MCH clinics, Axum town, Northern Ethiopia, 2013

\begin{tabular}{|c|c|c|c|c|}
\hline \multirow{2}{*}{ Variables } & \multicolumn{2}{|c|}{ Timely initiation of breast feeding } & \multirow{2}{*}{ COR (95\%C.I) } & \multirow{2}{*}{$\operatorname{AOR}(95 \% C I)$} \\
\hline & Yes $(\%)$ & No(\%) & & \\
\hline \multicolumn{5}{|l|}{ Child's sex } \\
\hline Male & $75(34.7)$ & $141(65.3)$ & 1.00 & 1.00 \\
\hline Female & $99(49.1)$ & $103(50.9)$ & $1.81(1.22,2.68)$ & $2.09(1.37,3.17)$ \\
\hline \multicolumn{5}{|l|}{ Maternal age (yrs) } \\
\hline $15-19$ & $9(52.94)$ & $8(47.1)$ & 1 & 1.00 \\
\hline $20-24$ & $66(61.7)$ & $41(38.3)$ & $0.67(0.25,1.94)$ & $0.58(0.11,1.70)$ \\
\hline $25-29$ & $97(57.4)$ & $72(42.6)$ & $0.84(0.31,2.27)$ & $0.84(.288,2.46)$ \\
\hline $30-34$ & $48(59.3)$ & $33(40.7)$ & $0.77(0.27,2.21)$ & $0.78(0.25,2.42)$ \\
\hline$\geq 35$ & $24(54.5)$ & $20(45.4)$ & $0.94(0.94,2.88)$ & $1.12(0.34,3.759)$ \\
\hline \multicolumn{5}{|l|}{ Educational status } \\
\hline Unable to read and write & $27(56.3)$ & $21(43.7)$ & 1.00 & 1.00 \\
\hline Grade1-8 & $128(59)$ & $89(41)$ & $0.92(0.49,1.72)$ & $0.91(0.47,1.77)$ \\
\hline Grade 9-12 & $72(55.8)$ & $57(44.2)$ & $1.01(0.52,1.99)$ & $0.99(0.48,2.06)$ \\
\hline College and above & $20(74.1)$ & $7(25.9)$ & $0.45(0.16,1.27)$ & $0.37(0.11,1.22)$ \\
\hline \multicolumn{5}{|l|}{ Place of delivery } \\
\hline Home & $13(36.1)$ & $23(63.9)$ & 1.00 & $1.30(0.63,2.69)$ \\
\hline Health institution & $161(42.2)$ & $221(57.8)$ & $1.29(0.63,2.62)$ & 1.00 \\
\hline \multicolumn{5}{|l|}{ Employment status } \\
\hline Employed & $22(40.7)$ & $32(59.3)$ & 1.00 & 1.00 \\
\hline Unemployed & $152(41.7)$ & $212(58.3)$ & $0.78(0.38,1.58)$ & $0.73(0.37,1.46)$ \\
\hline \multicolumn{5}{|l|}{ Mode of delivery } \\
\hline Normal & $165(42)$ & $228(58)$ & 1.00 & 1.00 \\
\hline $\mathrm{C} / \mathrm{S}$ & & & $0.35(0.10,1.24)$ & $.383(.10,1.45)$ \\
\hline other-assisted & $3(20)$ & $12(80)$ & $2.07(0.58,7.46)$ & $1.692(.44,6.47)$ \\
\hline Colostrums & $6(60)$ & $4(40)$ & & \\
\hline Yes & $103(54.8)$ & $85(45.2)$ & 1.00 & 1.00 \\
\hline No & $71(30.9)$ & $159(69.1)$ & $0.37(0.28,0.55)$ & $0.31(.205, .484)$ \\
\hline \multicolumn{5}{|l|}{ Frequency of ANC } \\
\hline$\leq 4$ times & $129(41.7)$ & $180(58.3)$ & 1.00 & 1.00 \\
\hline$>4$ times & $45(41.3)$ & $64(58.7)$ & $0.98(0.63,1.53)$ & $0.79(.48,1.29)$ \\
\hline
\end{tabular}

\subsection{Factors Associated with Exclusive Breastfeeding}

In the bivariate logistic regression analysis frequency of ANC, gestational age and starting colostrums within an hour after delivery had shown a statistically significant association with exclusive breastfeeding.

In multivariate analysis when adjusted for covariates all predictors except, initiation of colostrums within an hour, were not statistically significant predictors of exclusive breastfeeding. Meanwhile, adjusted for other covariates, mothers who didn't give colostrums to their newborn within an hour after birth were less likely to practice exclusive breastfeeding than mothers who gave colostrums within an hour after delivery $\mathrm{AOR}=0.13$ (95\% CI: 0.08 , 0.21 ) [Table 5].

\section{Discussion}

The study tries to determine the magnitude and factors associated with timely initiation and exclusive breastfeeding. The overall prevalence of timely initiation of breastfeeding was $41.6 \%$. Whereas $40.9 \%$ of the women were exclusively breast feed their child. In the multivariate logistic regression, the sex of the child and initiation of colostrums within an hour was a significant predictor of timely initiation of breastfeeding. And only the initiation of colostrums within an hour is a potent predictor of exclusive breastfeeding.

Breastfeeding is widely practiced across all subgroups of women and variations by background characteristics are small [4]. Besides, the ever breast feeding is universal in this study which is consistent with a national report of 
Ethiopia and studies done in Harae and South East region of Ethiopia [4,15,17]. However, it was higher as compared with a study done in Nigeria (82\%) [18]. The possible reason for high rate of breastfeeding in this population might be due to the variation in culture.

Infant feeding affects both the health of the mother and the child. Feeding practices affect the child's nutritional status, which in turn have a contribution for the risk of death. Timely initiation of breastfeeding is important for both the mother and the child [4]. Moreover, the prevalence of timely initiation of breastfeeding (41.6\%) observed in the study was congruent to the studies done in Nigeria (45\%) and Ghana $(41 \%)[19,20]$. But, it is much lower than other studies done national report of Ethiopia (52\%), North Jordan (86.6\%) and Nepal $(72.2 \%)[4,22,23]$. This might be due to the fact that women's in this study have some misconception like; insufficient release of breast milk (23.7\%), and a significant number of women did not get appropriate information $(12.4 \%)$. However, this finding was better than the study carried out in Turkey; only $35.2 \%$ initiated breastfeeding within the first hour after delivery [23].

Global strategy on infant and young child feeding, recommends feeding colostrums. Colostrum is produced in the first few days after delivery and provides natural immunity to the infant. It is recommended that children be fed colostrums immediately after birth and continue to be exclusively breastfed even if the regular breast milk has not yet let down [4]. Moreover, there is a good practice in this study in which $92.8 \%$ of mothers gave colostrums to their baby. This finding was broadly in line with the finding in Nepal (86\%) [22]. However, it was higher than a report on Nigerian women, which was $24 \%$ [24].

The practice of giving pre-lacteal feeds is discouraged because it limits the infant's frequency of suckling and exposes the baby to the risk of infection [4]. The prevalence of pre-lacteal feeding in this study was $11.72 \%$, which is in line with the finding of a South Gondar zone which was $11.1 \%$ [14]. However, it seems lower as compared with the national report of Ethiopia, in which, three out of ten children are given pre-lacteal feeds within the first three days of life [4] and finding from India which was 78\% [25]. This could be due to the fact that children whose mothers were assisted during childbirth by midwives are less likely to receive pre-lacteal feeds as compared with traditional birth attendants [4].

UNICEF and WHO recommend that children be exclusively breastfed during the first 6 months of life. Exclusive breastfeeding is recommended because breast milk is uncontaminated and contains all the nutrients necessary in the first few months of life [4].Moreover, the HSDP IV targets an increase in the proportion of exclusively breastfed infants under age 6 months to 70 percent by 2015 . However, this finding is low as compared with the HSDP IV target and the national report (52\%) [4].The overall prevalence of exclusive breastfeeding in this study was low (40.9\%), which is congruent with a studies conducted in Adwa town (41.8\%) and Ambo town
(42.3\%) [26,27]. The possible reason could be could be less effort and attention has been given by concerned leaders and health professionals towards TIBF and EBF.

Even though a study done in Mekelle indicated that child's sex was not statistically, associated with timely initiation of breastfeeding [16]. This study report that mothers with female child sex were more likely to initiate breastfeeding early as compared with their counterparts. This study is quiet different with a study done in Mekelle. The possible reason could be due to women may assume that female needs more care than male. The likelihood that a child is breastfed in the first hour after birth increases with the mother's educational status [4, 25, 28, 29]. However, educational status was not a predictor of exclusive breast feeding in this study.

ANC visit is an entry point for women to have contact with the health care providers and counseling on timely initiation and exclusive breast feeding. Having ANC visit makes the women to start timely initiation and exclusive breast feeding for the women [25].However, this finding shows that ANC visit were not a predictor of exclusive breast feeding which was similar with the national report $\mathrm{t}$ of Ethiopia, study done in, Adwa Town and Goba Woreda $[4,26,30]$

Mothers who didn't give colostrums to their newborn within an hour after birth were less likely to practice exclusive breast feeding than their counterparts. This finding was similar with the study conducted in South Gujarat region of India, providing colostrums within one hour of delivery was positively associated with exclusive breastfeeding and with the study conducted in Madagascar, showed that one of the reasons for failure to breastfeed exclusively for the recommended first six months of infant life is delay of the timely initiation breastfeeding [31,32]. The study faces the common limitation of cross sectional study which was difficult to assess cause effect relationship. And it does not include qualitative method of data collection and information from health care provide side which uses to explore the main reason for not having timely initiation of breast feeding as well as exclusive breast feeding.

\section{Conclusion}

This study revealed that the proportion of timely initiation and exclusive breast feeding was comparatively low. A significant number of mothers had positive attitude towards timely initiation and exclusive breast feeding. Providing colostrums within the first hour could have an influence on timely initiation and exclusive breast feeding.

\section{Acknowledgment}

We would like to thank Mekelle University, College of Health Sciences for funding this research. Our gratitude goes to supervisors, data collectors, TRHB, Axum administrator, respondent who participated in this study and Mekelle City administrator. 


\section{Competing Interests}

The authors declare that they have no competing interests.

\section{Authors' Contributions}

MA, KZ, KA, HY and HG designed the study, analyzed the data, drafted the manuscript and critically reviewed the article.

All authors read and approved the final manuscript.

Table 6. Factors associated with exclusive breast feeding among mothers who had infant 6-12 months in Axum town, Northern Ethiopia, 2013

\begin{tabular}{|c|c|c|c|c|}
\hline \multirow{2}{*}{ Variables } & \multicolumn{2}{|c|}{ Exclusive breast feeding } & \multirow{2}{*}{$\operatorname{COR}(95 \% \mathrm{CI})$} & \multirow{2}{*}{ AOR $(95 \% C I)$} \\
\hline & Yes $(\%)$ & No $(\%)$ & & \\
\hline \multicolumn{5}{|l|}{ Maternal age } \\
\hline $15-19$ & $6(35.3)$ & $11(64.7)$ & 1.00 & 1.00 \\
\hline $20-24$ & $40(37.4)$ & $67(62.6)$ & $1.09(0.37,3.20)$ & $0.51(0.15,1.71)$ \\
\hline $25-29$ & $73(43.2)$ & $96(56.8)$ & $1.39(0.49,3.95)$ & $0.94(0.29,2.99)$ \\
\hline $30-34$ & $34(42.0)$ & $47(58.0)$ & $1.32(0.45,3.94)$ & $0.95(0.28,3.24)$ \\
\hline$\geq 35$ & $18(40.9)$ & $26(59.1)$ & $1.27(0.40,4.06)$ & $1.19(0.32,4.49)$ \\
\hline \multicolumn{5}{|l|}{ Frequency of ANC } \\
\hline$\leq 4$ times & $40(26.14)$ & $113(73.85)$ & 1.00 & 1.00 \\
\hline$\geq 4$ times & $131(49.4)$ & $134(50.6)$ & $2.76(1.79,4.26)$ & $1.44(0.85,2.44)$ \\
\hline \multicolumn{5}{|l|}{ Employment } \\
\hline Employed & $19(35.2)$ & $35(64.8)$ & 1.00 & 1.00 \\
\hline Unemployed & $152(41.8)$ & $212(58.2)$ & $1.32(0.73,2.40)$ & $1.21(0.55,2.68)$ \\
\hline \multicolumn{5}{|l|}{ Educational status } \\
\hline Unable to read \&write & $16(33.3)$ & $32(66.7)$ & 1.00 & 1.00 \\
\hline Grade1-8 & $87(40.7)$ & $127(59.3)$ & $1.37(0.71,2.65)$ & $1.37(0.63,2.97)$ \\
\hline Grade 9-12 & $66(46.5)$ & $69(53.5)$ & $1.74(0.87,3.48)$ & $1.710(.73,3.99)$ \\
\hline College and above & $8(29.6)$ & $19(70.4)$ & $0.84(0.30,2.33)$ & $0.52(0.13,2.02)$ \\
\hline \multicolumn{5}{|l|}{ Gestational age } \\
\hline$\leq 9$-months & $143(38.96)$ & $224(61.03)$ & 1.00 & 1.00 \\
\hline$>9$ moths & $28(54.9)$ & $23(45.1)$ & $1.91(1.06,3.44)$ & $1.69(0.86,3.32)$ \\
\hline \multicolumn{5}{|c|}{ Does the child received colostrums within first hour } \\
\hline Yes & $122(64.9)$ & $66(35.1)$ & 1.00 & 1.00 \\
\hline No & $49(21.3)$ & $181(78.7)$ & $0.14(0.09,0.23)$ & $0.13(0.08,0.21)$ \\
\hline \multicolumn{5}{|l|}{ Child sex } \\
\hline Male & $97(44.9)$ & $119(55.1)$ & 1.00 & 1.00 \\
\hline Female & $77(36.6)$ & $128(63.4)$ & $0.71(0.48,1.05)$ & $1.38(0.88,2.17)$ \\
\hline \multicolumn{5}{|l|}{ Religion } \\
\hline Orthodox & $154(41.4)$ & $218(58.6)$ & 1.00 & 1.00 \\
\hline Moslem & $17(37.0)$ & $29(63)$ & $0.83(0.44,1.56)$ & $0.71(0.33,1.52)$ \\
\hline
\end{tabular}

Pp.404-422

\section{References}

[1] Kuldip K. International baby Food Action Network (IBFAN) BBP, IBFAN-Asia, (October 2007), 1-2

[2] Alive and Thrive 1825 Connecticut Ave., NW, Washington, D.C. 2009-5721@fhi360 (360, Alive and thrive initiative).

[3] Stuart C, Christoph L. Obstetrics by Ten Teachers. Amesterdam: New York; 2000, 17th edition.

[4] Central Statistical Agency [Ethiopia] and ICF International. Ethiopia Demographic and Health Survey 2011. Addis Ababa, Ethiopia and Calverton, Maryland, USA: Central Statistical Agency and ICF International, 2012

[5] The state of the Better world's breastfeeding: report card. Initiation of breastfeeding within 1 hour.2008; 10, 19-38

[6] Scott JA, Aitkin I, Binns CW, Aroni RA. Factors associated with the duration of breastfeeding amongst women in Perth, Australia. Act Paediatrica. 1999 Apr; 88(4):41621.

[7] European Journal scientific research, (C) Euro Journals Publishing, Inc. 2010, ISSN 1450216X Vol.40 No.3 (2010),
[8] Lauer JA, Betran AP, Barros AJ, and de Onis M. Deaths and years of life lost due to suboptimal breast-feeding: Public Health Nutrition 2006; 9:673-685.

[9] Edmond KM, Zandoh C, and Quigley MA: Delayed breastfeeding initiation increases risk of neonatal mortality. Pediatrics 2006, 117:380-386.

[10] K, Cagliari A. Initial management of breastfeeding. Sep, $2001 ; 64: 981-8$

[11] Ampeire Isaac Petit. Uropean Journal of Health and knowledge on exclusive breast feeding. August 2008, Vol 23, No 1

[12] TRHB. Tigray regional health bureau profile for the 20011/12 EFY. Tigray, Mekelle, 2013

[13] Hegney D, Fallon A, Crepinsek M, and O'Brien M, Doolan J. Against all odds: Toowoomba University of Queensland 2005. Report No: ISBN 090975683

[14] Ministry of finance and economic development population department an annotated bibliography of population and reproductive health researches in Ethiopia, 2002-2007 December, 2008 p 24-28 
[15] Alemayehu T, Haidar J, Habte D: Determinants of exclusive breastfeeding practices in Ethiopia. Ethiop J Health Dev 2009, 23(1):12-18

[16] Hailemariam B. Determinants of breast feeding practice among mothers of children age less than 24 months attending maternal and child health clinics in Mekelle town, 2011, grey literature

[17] Singh B. Knowledge, Attitude and Practice of Breast Feeding - A Case Study, the European, Journal of Scientific Research, 201040 (3) pp.404-422.

[18] Salami L. factors influencing breastfeeding practices Edo state, Nigeria, African journal of food, agriculture, nutrition and development, 2006.

[19] Ojo M Agunbiade, Opeyemi V Ogunleye, Constraints to exclusive breastfeeding practice among breastfeeding mothers in Southwest Nigeria: implications for scaling up, International Breastfeeding Journal 2012, 7:5 doi:10.1186/1746-4358-7-5.

[20] 20. LINKAGES, Experience: Result final report http://www.linkages project.org /media/ publications / Results 11-06.pdf] web site Ghana, 2006.

[21] Khassawneh M, Khader Y, and Amarin Z: Knowledge, attitude and practice of breastfeeding in the north of Jordan a cross-sectional study. International Breastfeeding Journal 2006, 1:17

[22] Chandrasekhar TS, Joshi HS, and Binu VS: Breast-feeding initiation and determinants of exclusive breast-feeding: A questionnaire survey in an urban population of western Nepal. Public Health Nutrition 2007, 10(2):192-9.

[23] Orun E. factors associated with breastfeeding initiation time in a Baby-Friendly Hospital. Turkish J Pediatric 2010; 52: $10-16$
[24] Davies. A, Anita A. Socio cultural factors and the promotion of exclusive breastfeeding in rural Yoruba communities of Osun State, Nigeria, journal Social Science \& Medicine,1997;45 (1) : 113-125

[25] Setegn T, Gerbaba M. Breastfeeding and Pre-Lacteal Feeding Rates in Hospital Delivered Babies in India and Associated Factors, Pediatric Research (2011) 70, 52-52; doi:10.1038/pr.2011.277

[26] Getachew G. feeding profile and diarrhoea morbidity among infants of 7-12 months" Adua town, Tigray, north Ethiopia 2006, master's thesis

[27] Lense G. Tefera B. and Fasil T.fators affecting adherence to exclusive breastfeeding practice in Ambo town and Ambo Woreda; EPHA 20th Annual public health conference, 2009.

[28] UNICEF: SriLanka statistics http://www.unicef.org/ progressforchildren/2006n 4 /index breast feeding .html web site UNICEF: 2012. New York: UNIFEF

[29] Uchendu U. O. Ikefuna A. N. and Emodi I. J. Factors associated with exclusive breastfeeding among mothers seen at the University of Nigeria Teaching Hospital. S.A journal of child health, 2009; 3(1): 14-19

[30] Gerbaba et al; Determinants of timely initiation of breastfeeding among mothers in Goba Woreda, South East Ethiopia: licensee Biomed Central Ltd (C) 2011

[31] Chudasama R. Patel P. \& Kavishwar A. Breastfeeding initiation practice and factors affecting breastfeeding in South Gujarat region of India. The Internet Journal of Family Practice. 2009; 7

[32] Guyon A, et al. LINKAGES global program that seeks to increase breastfeeding and related practices to improve maternal reproductive health, Final Report: The Madagascar, LINKAGES Project, 2006 